\title{
The Impact of Climate Change on Precipitation-related Insurance Risk: A Study of the Effect of Future Scenarios on Residential Buildings in Norway
}

\author{
Ida Scheel $^{\mathrm{a}}$ and Mikkel Hinnerichsen ${ }^{\mathrm{b}}$ \\ ${ }^{a}$ Department of Mathematics, University of Oslo, P.O. Box 1053 Blindern, Oslo 0316, Norway. \\ ${ }^{\mathrm{b}}$ Gjensidige Forsikring, Oslo, Norway. \\ E-mail: Mikkel.Hinnerichsen@gjensidige.no
}

Climate change is likely to increase the future risk of weather-related damage to buildings worldwide. This challenge is faced by society in general, but the insurance industry is particularly important in the management of the anticipated increase in future risk. In addition to adjusting premiums appropriately and gradually, they can play an important role in prevention. It is crucial to know which areas are vulnerable and to what extent. In this paper, a spatial regression model for linking weather-related insurance losses for residential buildings to meteorological and hydrological covariates is coupled with three plausible scenarios for the future climate in order to project the future number of weatherrelated residential building insurance losses in Norway. The model is trained on observed daily insurance loss and weather data at the municipality level. Our results indicate a dramatic increase in the projected future weather-related insurance risk in many parts of Norway. The procedure can be extended and applied to other areas globally.

The Geneva Papers (2012) 37, 365-376. doi:10.1057/gpp.2012.7

Keywords: climate change impact; risk projections; insurance risk; society risk; risk management

\section{Introduction}

It is important that the insurance sector is robust to the potential risk changes due to climate change. Because of relatively short contract periods, the insurance sector is to some extent able to cope with increasing risk by adjusting premiums. However, there is a danger of insufficient and/or delayed risk adjustment. ${ }^{1}$ It is obviously advantageous for insurance companies to know of potential dramatic risk changes as early as possible, in order to prepare for the necessary adjustments such as a smoother rather than an abrupt premium increase, or seeing potential new business opportunities such as new types of insurance products. The adjustments obviously need to be balanced with the risk of losing reputation and market-share involved with raising premiums or making areas un-insurable, which the authorities will not even always allow. For the public and planning authorities, it is of great importance to know of areas in danger of becoming un-insurable, where it is not wise to plan new buildings or where protective measures should be put in place.

\footnotetext{
${ }^{1}$ Botzen et al. (2010).
} 
Vellinga $e t$ al. $^{2}$ and Mills ${ }^{3}$ early on highlighted the need for a better understanding of the consequences of climate change for the insurance sector, regarding both extreme and ordinary weather events, and helped put a focus on the role and challenges of the insurance industry imposed by climate change. The insurance sector around the world has become increasingly committed to dealing with the possible effects of climate change. The risks and opportunities of climate change facing the insurance sector is a fast-growing field of commercial research and development. ${ }^{4}$ The emphasis is on facing the increasing risks involved and to see new business opportunities, but also to contribute to adaptation and mitigation, for example by influencing and collaborating with governments, or by using premium incentives to encourage risk preventive actions or motivate green industry and building practices. Prior to the United Nations Climate Change Conference in Copenhagen in 2009, ClimateWise ${ }^{5}$ called for the developed countries to commit to a reduction in greenhouse gas emissions of 40 per cent by $2020 .^{6}$

The consequences of climate change for the insurance sector is a growing field of research also in academia. ${ }^{7}$ There is however a lack of academic case-studies on the effect of climate change scenarios on insurance risk. This can partly be attributed to a lack of available insurance data mainly due to insurance companies being very protective of their data. Haug et al. ${ }^{8}$ model the daily number of weather-related insurance losses in each of the 19 counties of Norway separately and use climate scenarios for 2071-2100 to project future insurance losses. They show a significant increase in the insurance risk. While the regional downscaled climate projections have since been improved upon, there are still considerable weaknesses in projecting the correct distribution of precipitation. In a new study, Orskaug et al. ${ }^{9}$ evaluate regional downscaled climate models by comparing the projected precipitation distribution for 1961-2000 to the historical meteorological records. The results show among other things that higher levels of precipitation are underestimated. What is well-established, however, is that we are in fact facing climate change and it is useful to consider different plausible scenarios of the future climate to investigate what the impacts might be. Given that the future regional downscaled climate projections are associated with such great uncertainty, it makes sense to do a simple study of the effect of plausible increases in precipitations compared to a present-climate reference year. Scheel et al. ${ }^{10}$ propose a coherent spatial model for the daily number of weather-related insurance losses at the municipality level, fitted to the same historical insurance loss data for

\footnotetext{
${ }^{2}$ Vellinga et al. (2001).

${ }^{3}$ Mills (2005).

${ }^{4}$ See for example Association of British Insurers (2009), CEA (2009), Dlugolecki (2008), Mills (2009).

${ }^{5}$ ClimateWise is a global collaboration network of leading insurers, facilitated by the University of Cambridge, aiming at facing climate change (see www.climatewise.org.uk).

${ }^{6}$ ClimateWise NEWS RELEASE October 2009, see www.climatewise.org.uk/news/2009/10/22/newsrelease-climatewise-calls-for-40-emission-cuts-by-2020.html.

${ }^{7}$ See for example Botzen and van den Bergh (2008); Hecht (2008); Botzen et al. (2010); Phelan et al. (2010).

${ }^{8}$ Haug et al. (2011).

${ }^{9}$ Orskaug et al. (2011).

${ }^{10}$ Scheel et al. (2011, 2012).
} 
residential buildings as used by Haug et al. ${ }^{8}$ The present paper uses the resulting posterior predictive distribution (PPD) for the number of losses to project the distribution of the yearly number of losses for each municipality for different scenarios corresponding to the low, medium and high climate projections for Norway in 20712100 reported in Hanssen-Bauer et al. ${ }^{11}$ The projections are compared to the PPD of a reference year in the present climate. It is assumed that the residential building stock is the same in the future period 2071-2100 as in the reference year. Because contracts for insuring residential buildings are generally for one year, the potential increase in the total yearly number is of particular interest. This illuminates how the weather-related insurance risks of different areas of Norway are likely to change due to plausible scenarios of climate change. As in Haug et al. ${ }^{8}$ and Scheel et al., ${ }^{10}$ the focus is on insurance for residential buildings. The results show that the scenarios considered entail significant increases in the number of losses for the most populated areas of Norway, with quite dramatic risk changes for many municipalities. This calls for action, by both the insurance sector and the authorities. Improved building requirements and careful consideration of the location of new residential buildings should be considered alongside appropriate increased insurance premiums. Our results also indicate the need for further research, for example similar studies for other areas, and in the future coupled with adequate regional downscaled climate projections.

This paper is organised as follows. In the next section, the data and methodology are described. The results are presented in the subsequent section, and the last section concludes with a brief discussion of the findings and their implications.

\section{Materials and methods}

\section{Data}

The basis for the model we use for projecting insurance losses for the future scenario climates is the PPD found in Scheel et al. ${ }^{10}$ This distribution (described in more detail in the next section) results from fitting the proposed model to observed training data, hence obtaining the posterior distribution of the parameters given the training data, which in turn provides the PPD of new data conditioned on the training data. The data set used in Scheel et al. ${ }^{10}$ and the present paper consists of daily loss counts and number of insurance policies (exposure) for central and south Norway at the municipality level ( $K=319$ municipalities) for the period $1997-2006$, as well as meteorological and hydrological data (covariates) at the same temporal and spatial resolution. The insurance data was provided by the largest non-life insurance company in Norway, ${ }^{12}$ and contains losses from all insured residential buildings due to damages caused by either precipitation, surface water, snow melting, undermined drainage, sewage back-flow or blocked pipes. The total number of losses in the data set is 29,673 . The data set does not include a small number of catastrophic weather-related events, which in Norway are covered by a separate national fund and hence are not available

\footnotetext{
${ }^{11}$ Hanssen-Bauer et al. (2009).

12 Gjensidige, www.gjensidige.no.
} 
in the loss data set from the insurance company. See Haug et al. ${ }^{8}$ for a more detailed description of the data. The meteorological and hydrological data include daily mean precipitation $\left(R_{t}\right)$, mean temperature $\left(C_{t}\right)$, drainage run-off $\left(D_{t}\right)$ and snow water equivalent $\left(S_{t}\right)$, which was collected and processed by the Norwegian Meteorological Institute ${ }^{13}$ and the Norwegian Water Resources and Energy Directorate. ${ }^{14}$ In addition to these four basic variables, the covariates in the model include the three derived variables precipitation on the previous day $\left(R_{t-1}\right)$, the sum of precipitation in the previous three days $\left(R_{3 t}\right)$ and the change in snow water equivalent $\left(S_{\Delta}\right)$. The training data set used for fitting the model in Scheel et al. ${ }^{10}$ consisted of the nine years of data, which remains when the year 2001 is excluded. The data for the year 2001 (which is in the middle of the observation period 1997-2006) was left out from the posterior analysis and preserved for evaluating the PPD in Scheel et al. ${ }^{10}$ In this paper the data for the year 2001 serves as the reference ("baseline") for the scenario data investigated.

The Norwegian government appointed NOU-Climate Change Adaptation committee, in Hanssen-Bauer et al., ${ }^{11}$ reports an increase in precipitation of 5 per cent, 18 per cent and 30 per cent on a yearly basis for Norway as a whole from the period 1961-1990 to the future period 2071-2100. The low (5 per cent) increase corresponds to the 10-percentile, the medium (18 per cent) to the median value and the high (30 per cent) to the 90-percentile of a dynamic downscaling ensemble for the change from 1961-1990 to 2071-2100. The increase is in percentage from the middle value in the period 1961-1990 to the middle value in the future period 2071-2100. The ensemble is based on 22 climate projections from different regional climate models, with the emission scenario inputs $\mathrm{B} 1\left(\mathrm{CO}_{2}\right.$-concentration of $380 \mathrm{ppm}$ in 2100$)$, $\mathrm{A} 1 \mathrm{~B}$ $\left(\mathrm{CO}_{2}\right.$-concentration of $703 \mathrm{ppm}$ in 2100$)$ and $\mathrm{A} 2\left(\mathrm{CO}_{2}\right.$-concentration of $836 \mathrm{ppm}$ in 2100). See Hanssen-Bauer et al. ${ }^{11}$ for more details on the ensembles. The high increase seems to agree with the observed increase in the last 30 years. ${ }^{15}$ The scenario meteorological and hydrological data used in this paper is derived from the 2001 data by increasing the precipitation covariate $R_{t}$ by 5 per cent (Scenario1), 18 per cent (Scenario2) and 30 per cent (Scenario3). The reasoning for restricting the focus to plausible increases in precipitation is that the variable selection results in Scheel et al. ${ }^{10}$ show that precipitation is the most important factor for explaining the risk. The covariates derived from the daily precipitation $\left(R_{t-1}\right.$ and $\left.R_{3 t}\right)$ are increased accordingly and the numbers of insurance policies in municipality $k$ at day $t\left(A_{k t}\right)$ are the same as in the original 2001 data.

\section{The PPD for the number of insurance losses}

The projections of the number of insurance losses are based on the model introduced in Scheel et al. ${ }^{10}$ for the link between weather events and weather inflicted insurance losses. The number of losses in a municipality on a daily resolution is modelled by a Bayesian Poisson Hurdle (BPH) model with the meteorological and hydrological

\footnotetext{
13 www.met.no.

${ }^{14}$ www.nve.no.

${ }^{15}$ See Figure 5.2.11 in Hanssen-Bauer et al. (2009).
} 
covariates $R_{t}, C_{t}, D_{t}, S_{t}, R_{t-1}, R_{3 t}$ and $S_{\Delta}$ (described in the previous section). The number of losses $N_{k t}$ at day $t(t=1, \ldots, T)$ for municipality $k(k=1, \ldots, K)$ is modelled as

$$
P\left(N_{k t}=n \mid \alpha_{k t}, \lambda_{k t}\right)=\alpha_{k t} \cdot \mathbf{1}_{n=0}+\left(1-\alpha_{k t}\right) \frac{\lambda_{k t}^{n}}{\left(\exp \left(\lambda_{k t}\right)-1\right) n !} \cdot \mathbf{1}_{n>0} .
$$

This is a two-part model where the first part, the Hurdle, is a Bernoulli distribution for the binary event of presence or absence of insurance losses, with probability $\alpha_{k t}$ for no loss and $1-\alpha_{k t}$ for one or more losses at day $t$ for municipality $k$. The second part is a Positive Poisson distribution for the number of losses in the event of "clearing the Hurdle", that is when there is a presence of losses with parameter $\lambda_{k t}$. The Positive Poisson distribution is derived from the ordinary Poisson distribution by conditioning on a value larger than 0 . The rationale behind using this BPH model is that there is thought to be one process determining whether or not losses occur, and then if losses occur, another process controls the actual number. The values of the covariates $R_{t}, C_{t}, D_{t}, S_{t}, R_{t-1}, R_{3 t}$ and $S_{\Delta}$ for municipality $k$ at day $t$ are organised in the vector $\mathbf{x}_{k t}$, and enter the model through two generalised linear models, one for $\alpha_{k t}$ in the Hurdle part

$$
\operatorname{logit}\left(\alpha_{k t}\right)=\beta_{k 0}^{\alpha}+\mathbf{x}_{k t} \boldsymbol{\beta}_{k}^{\alpha}
$$

for all days $t$ in municipality $k$, and one for $\lambda_{k t}$ in the Positive Poisson part

$$
\log \left(\lambda_{k t}\right)=\beta_{k 0}+\mathbf{x}_{k t} \boldsymbol{\beta}_{k}^{\lambda}+\log \left(A_{k t}\right)+\varepsilon_{k t}, \varepsilon_{k t} \sim \operatorname{Normal}\left(0, \sigma_{k}^{2}\right)
$$

for the days $t$ with a presence of losses in municipality $k$. Notice that this is normalised by the number of insurance policies $A_{k t}$ in the municipality at day $t$.

Because the effects of the covariates are thought to vary depending on municipalityspecific characteristics such as for example building traditions and sewage systems, the regression coefficients $\beta_{k 0}^{\alpha}, \boldsymbol{\beta}_{k}^{\alpha}, \beta_{k 0}^{\lambda}$ and $\boldsymbol{\beta}_{k}^{\lambda}$ are municipality-specific. Also, Bayesian variable selection and model averaging is performed locally for each municipality, but are spatially linked by an Ising model controlling spatial dependence between neighbouring municipalities of the selection of which variables are important. See Scheel et al. ${ }^{10}$ for more technical details on the Bayesian variable selection and also a presentation of results of the posterior analysis, which was performed by Markov Chain Monte Carlo (MCMC) simulation.

The PPD used in this paper for projecting insurance losses for future scenarios is obtained as a by-product of the posterior MCMC simulation used for fitting the model to the training data in Scheel et al. ${ }^{10}$ Each of the $M=10,000$ draws from the posterior distribution of the parameters facilitates one draw from the PPD for the unobserved number of insurance losses at a given day for each municipality, conditioned on the covariates for that day and the training data. Hence, the posterior simulation used for fitting the model in Scheel et al. ${ }^{10}$ in turn provides $M=10,000$ draws from the PPD for the daily number of insurance losses for each municipality. Technical details on the PPD can be found in Scheel et al. ${ }^{10}$ From the $M$ draws from the daily PPD, $M$ draws from the PPD for the aggregated yearly number of losses in each municipality is easily 
obtained by, for each of the $M$ draws from the PPD, summing all the daily number of losses in a municipality. For obtaining the PPDs, the MCMC simulation algorithms described in Scheel et al. ${ }^{10}$ (implemented in a combination of C and R) were used.

In order to test a null hypothesis that two population distributions are identical against the alternative that one population is stochastically smaller than the other, the non-parametrical one-sided Kolmogorov-Smirnov two-sample test can be used. ${ }^{16}$ In this paper, this test is used to test whether the PPD of the yearly number of losses for the reference year 2001 is identical to the PPD of the yearly number for the three scenarios. The alternative hypotheses are that the yearly number of losses for the reference year 2001 is stochastically smaller than the yearly number for the three scenarios. The test uses the posterior predictive cumulative distribution functions of the yearly number of losses for the two samples, call these $F_{k, 2001}(x)$ and $F_{k, \text { Scl }}(x)$ for the reference year 2001 and Scenario1 for municipality $k$. The test statistic $D_{k, 1}$ for testing whether the PPD of the yearly number of losses for the reference year 2001 is identical to the PPD of the yearly number for Scenario1 for municipality $k$ is then the supremum of all distances between these two: $D_{k, 1}=\sup \left|F_{k, 2001}(x)-F_{k, \mathrm{Scl}}(x)\right|$. Under the null hypothesis $\sqrt{T / 2} D_{k, 1}$ (with $T=365$ days) follows the Kolmogorov distribution, and hence a $p$-value can be found. The tests were performed by using the $R$ function ks.test.

\section{Results}

Figure 1 shows maps of the results of the Kolmogorov-Smirnov tests comparing the PPD of the yearly number of losses for the reference year 2001 to the PPD of the yearly number for (a) Scenario1, (b) Scenario2 and (c) Scenario3 for each municipality. For 16 municipalities, including the coastal cities Sarpsborg, Fredrikstad, Tønsberg, Larvik, Andebu, Lillesand, Farsund and Bergen (the second largest city in Norway and the city with the highest exposure today), the yearly number of losses for the reference year 2001 is significantly stochastically smaller than the yearly number for all three scenarios. For the capital Oslo, the yearly number of losses for the reference year 2001 is significantly stochastically smaller than the yearly number for both Scenario2 and Scenario3. The reference year 2001 is significantly stochastically smaller than the yearly number for Scenario2 and Scenario3 for 99 ( 31 per cent) and 133 (42 per cent) of the municipalities, respectively. Most of these municipalities are in the highly populated coastal areas. For data from discrete distributions, the Kolmogorov-Smirnov test has been shown to be conservative. ${ }^{17}$ This means that some of the null hypotheses may incorrectly be accepted in Figure 1. But it also means that the ones that are rejected really indicate that the yearly number of losses for the reference year 2001 is stochastically smaller than the yearly number for the scenario under consideration at the given significance level ( 5 per cent).

It is also of interest to compare different properties of the distributions. Figure 2 shows maps of the percentage increase of the posterior predictive mean of the yearly number of losses for the three scenarios for each municipality. The loss increases vary

\footnotetext{
${ }^{16}$ See for example Gibbons and Chakraborti (1992).

${ }^{17}$ Goodman (1954), Gibbons and Chakraborti (1992).
} 

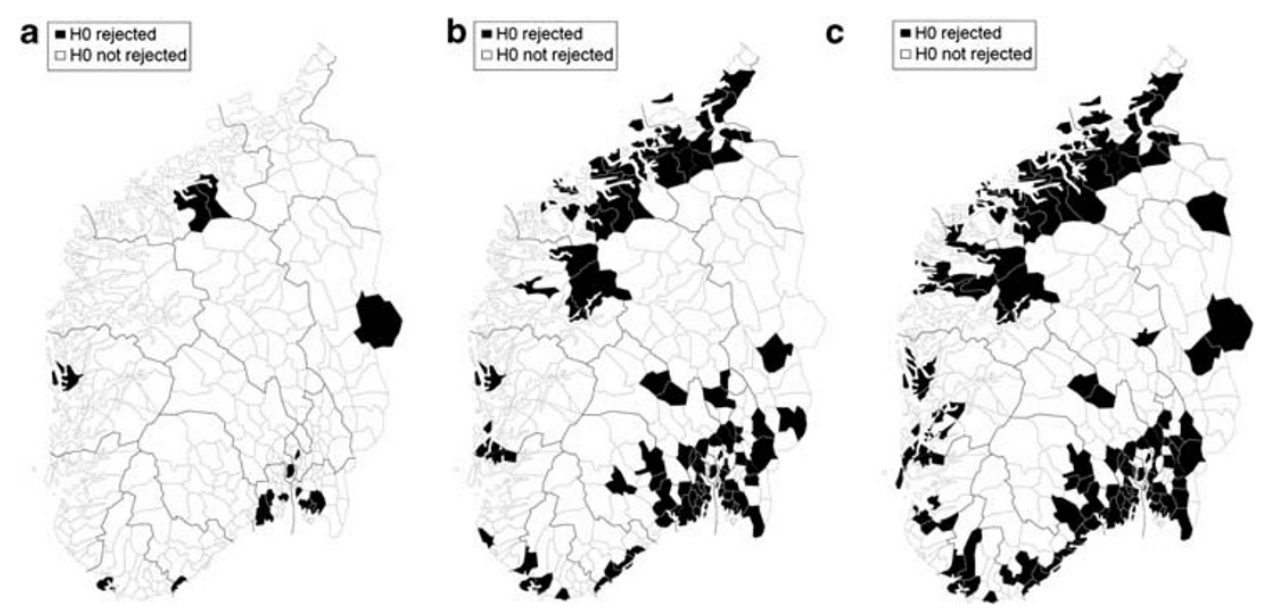

Figure 1. Maps of the central and south of Norway, divided into the municipalities, showing the results of the (one-sided) Kolmogorov-Smirnov test of the null hypothesis $\left(\mathrm{H}_{0}\right)$ that the posterior predictive distribution of the yearly number of losses for the reference year 2001 is identical to the posterior predictive distribution of the yearly number of losses for (a) Scenario1, (b) Scenario2 and (c) Scenario3, against the alternative that the yearly number of losses for the reference year 2001 is stochastically smaller than the yearly number for the three scenarios. The significance level is 5 per cent.

quite a lot across the country for all three scenarios. To consider this increase in the posterior predictive mean from the reference climate to the scenario is comparable to considering the change in Eq. (4.8) in Haug et al. ${ }^{8}$ The increases tend to be higher in the coastal areas for all three scenarios, of course with the highest increases for Scenario3. It is interesting to synthesise the results in Figure 2 with the ones from Figure 1, considering the increases in the means for the municipalities where the null hypotheses were rejected in the Kolmogorov-Smirnov tests (the KS significant municipalities). For Scenario1, the KS significant municipalities Nesodden, Tønsberg, Larvik, Andebu, Lillesand, Fjell, Askøy and Nesset show more than 10 per cent increase in the means. For Scenario2, 21 of the KS significant municipalities show more than 50 per cent increase in the means, among which are the cities Moss, Tønsberg, Lillesand and Grimstad. The last three are of the KS significant municipalities for Scenario3 that experience increases in the means of between 100 and 200 per cent Scenario3, while Moss together with Råde, Hurum, Re and Flekkefjord actually show increases of beween 200 and 300 per cent for Scenario3.

It is also interesting to look at the change in the more extreme, less likely events such as the 95-percentile. Figure 3 shows maps of the percentage increase of the 95-percentile of the PPD of the yearly number of losses for the three scenarios for each municipality, which also vary quite a lot spatially. Comparing Figures 2 and 3 we see that more municipalities do not experience an increase in the 95-percentile (Figure 3) than what was the case for the mean (Figure 2). Many of these municipalities experienced a moderate increase in the mean. However, some municipalities experience a much more dramatic increase in the 95-percentile than what is seen for 

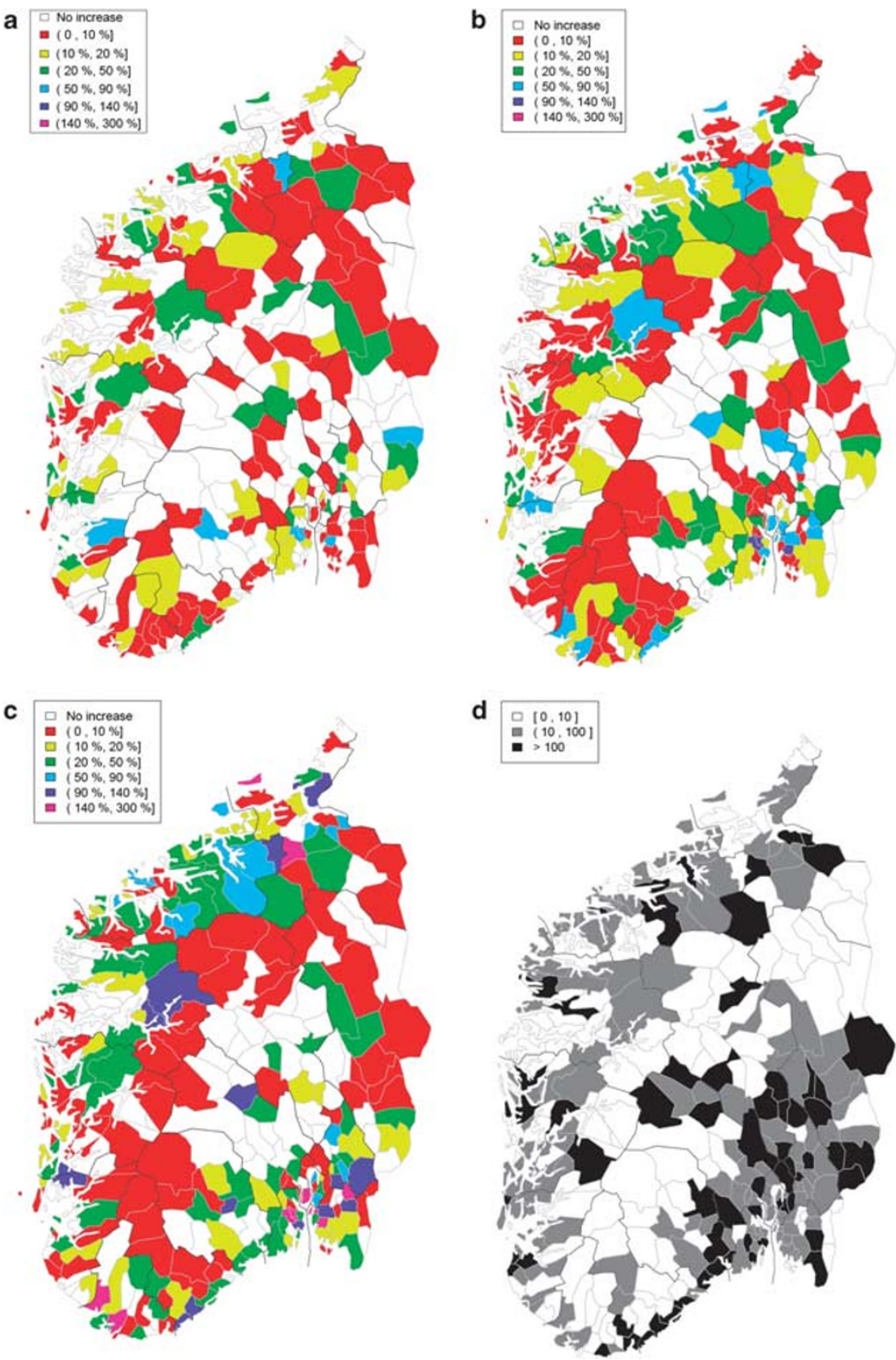

Figure 2. Maps of the central and south of Norway, divided into the municipalities, showing the percentage increase of the posterior predictive mean of the yearly number of losses for (a) Scenario1, (b) Scenario2 and (c) Scenario3, all compared to the reference year 2001, while (d) shows a map of the mean of the posterior predictive distribution of the yearly number of losses for the observed weather of the reference year 2001 . 

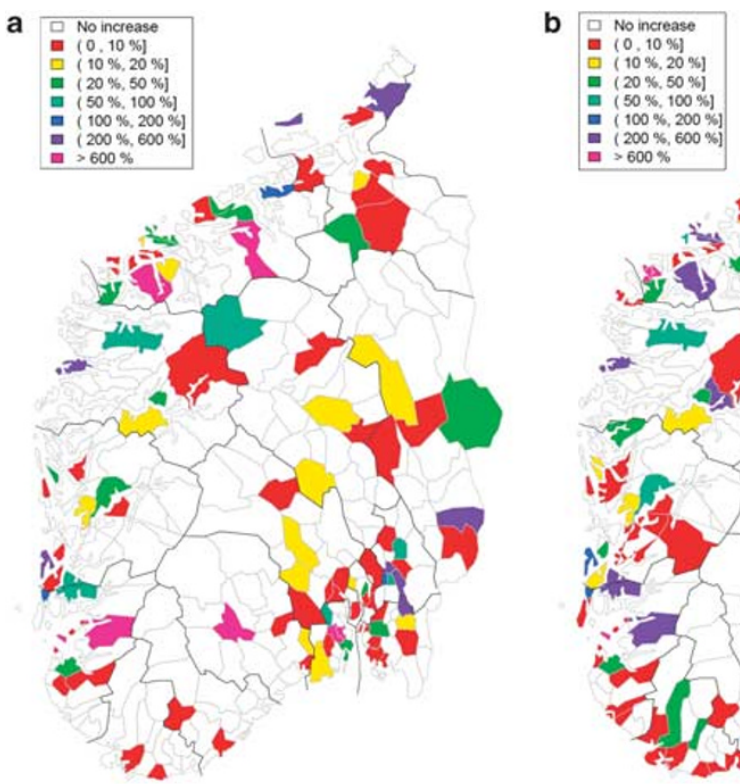

373
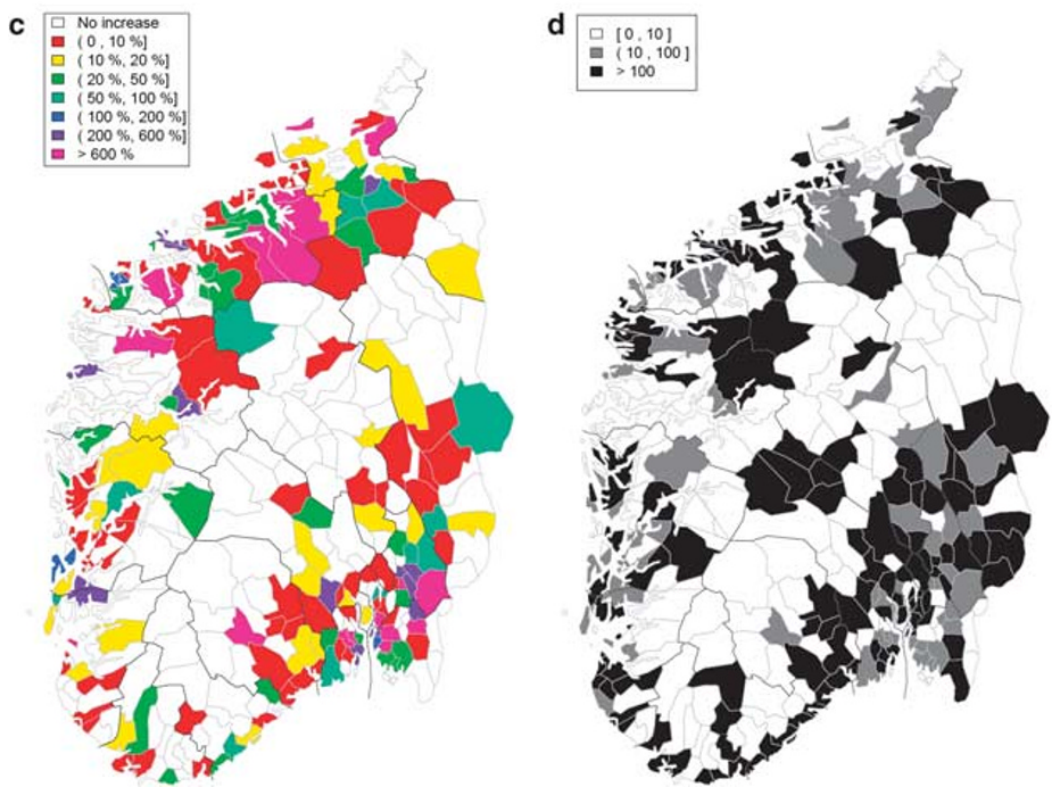

Figure 3. Maps of the central and south of Norway, divided into the municipalities, showing the percentage increase of the posterior predictive 95-percentile of the yearly number of losses for (a) Scenario1, (b) Scenario2 and (c) Scenario3, all compared to the reference year 2001, while (d) shows a map of the 95-percentile of the posterior predictive distribution of the yearly number of losses from "original 2001 weather". 
the mean, some even for Scenario1. Comparing the results in Figure 3 to the ones from Figure 1, we see that for Scenario1, the KS significant municipalities Nesodden, Trysil, Tønsberg, Ask $\varnothing \mathrm{y}$ and Nesset show more than 20 per cent increase in the 95-percentiles. For Scenario2, 19 of the KS significant municipalities show more than 100 per cent increase in the 95-percentiles, among which are the cities Moss and Tønsberg. Of the KS significant municipalities for Scenario3, 25 experience increases in the 95-percentiles of more than 200 per cent, which include Moss and Tønsberg.

\section{Conclusion}

The results in this paper indicate quite dramatic changes in the risks of precipitationrelated damages to residential buildings as a result of plausible climate change scenarios. The loss changes found in this study exceed the ones found in Haug et al., ${ }^{8}$ where increases in the number of losses of up to 30 per cent were reported. Our results show that some areas and municipalities in Norway seem to be very vulnerable. Even for the very moderate Scenario1, highly populated municipalities can expect over 10 per cent increase in the mean number of losses, that is twice the percentage increase in precipitation, and over 20 per cent increase in the 95-percentile. For the other two scenarios the results are much more dramatic, with many municipalities showing over 50 per cent increase in the mean and over 100 per cent increase in the 95-percentile under Scenario2. Under Scenario3, this risk is more than doubled for many municipalities compared to the results for Scenario2. As mentioned in the description of the data, Scenario3 apparently coincides with the observed increase in precipitation the last three decades. The fact that there seems to be a tendency that the coastal municipalities are more vulnerable than inland ones may be explained by both that they are more densely populated, and also that they generally get more precipitation.

These results show that preventive measures are needed for many areas of Norway. Both authorities and the insurance industry should be proactive in reducing these potential future risk increases by giving incentives and/or requirements for improved residential building traditions (with respect to both building quality and location). The insurance companies should also consider pricing these potential future risk increases appropriately. Insurance premiums could be increased by considering the municipality specific projected increase of the mean number of yearly losses. Some areas with the highest projected increase in future risk should maybe even be considered un-insurable in the future.

Even though Scenario3 entails quite a dramatic increase in precipitation (30 per cent), actually practically all the daily scenario data was within the range seen in the training data used for estimating the PPD. Only 12 (Scenario1), 29 (Scenario2) and 66 (Scenario3) out of the $365 \times 319$ days had precipitation higher than what was seen in the training data, affecting at most 4 days per municipality, see Figure 4 . Hence, there is very little extrapolation involved when using the PPD for the scenarios. Also, the municipalities affected by extrapolation are mostly located in areas of Norway where the results did not point to severe risk increases.

The methodology for projecting and communicating future weather-related damages used in this paper can be applied also for case studies in other countries. 

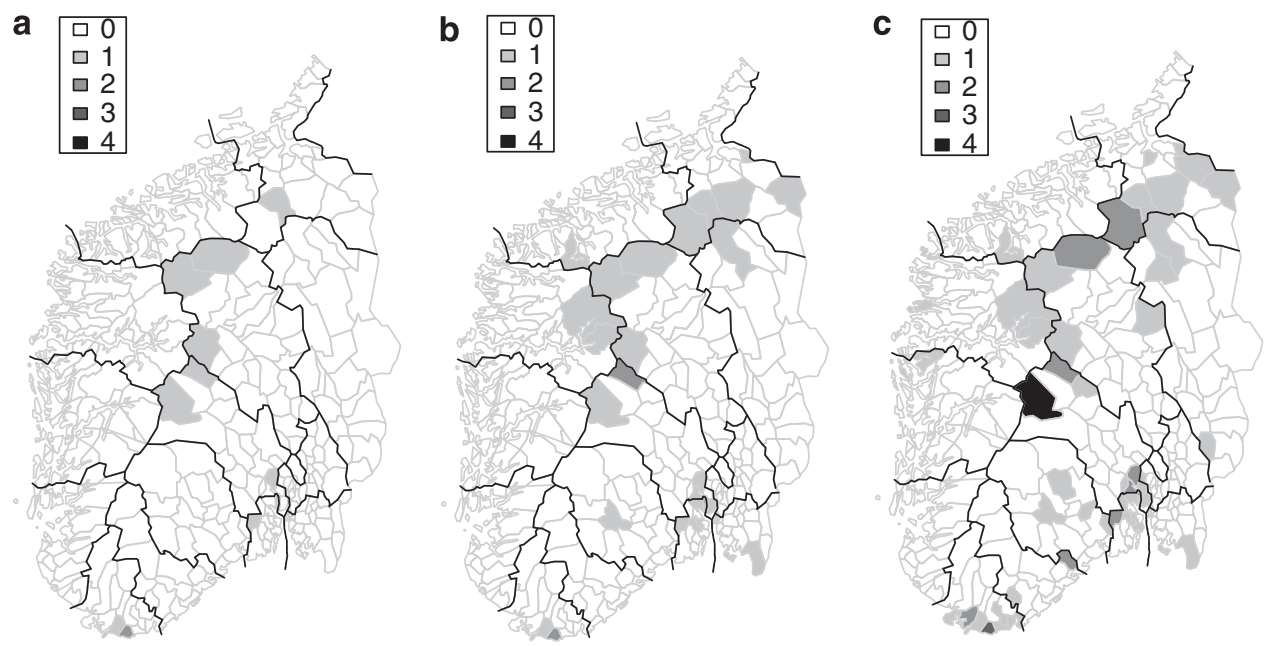

Figure 4. Maps of the central and south of Norway, divided into the municipalities, showing the number of days with scenario precipitation outside of the training range for (a) Scenario1, (b) Scenario2 and (c) Scenario3. Of the days with extrapolation, the median of the ratio between the scenario precipitation and the maximum precipitation seen in the training data was 1.1 .

Our results clearly indicate the need for such studies elsewhere. When regional downscaled climate projections are improved and found satisfactory, they should substitute the simpler scenarios considered in this paper, providing better insurance loss projections for the future.

\section{References}

Association of British Insurers (2009) 'The financial risks of climate change', ABI Research Paper, from www.abi.org.uk/Publications/ABI_Publications_The_Financial_Risks_of_Climate_Change_59e.aspx, accessed 22 October 2010.

Botzen, W.J.W. and van den Bergh, J.C.J.M. (2008) 'Insurance against climate change and flooding in the Netherlands: Present, future, and comparison with other countries', Risk Analysis 28: 413-426.

Botzen, W.J.W., van den Bergh, J.C.J.M. and Bouwer, L.M. (2010) 'Climate change and increased risk for the insurance sector: A global perspective and an assessment for the Netherlands', Natural Hazards 52: $577-598$.

CEA (2009) 'Tackling climate change: The vital contribution to insurers', CEA Insurers of Europe, from www.cea.eu/uploads/DocumentsLibrary/documents/1259775921_tackling-climate-change.pdf, accessed 22 October 2010.

Dlugolecki, A. (2008) 'Climate change and the insurance sector', The Geneva Papers on Risk and InsuranceIssues and Practice 33(1): 71-90.

Gibbons, J.D. and Chakraborti, S. (1992) Nonparametric Statistical Inference, Chap. 7.3, 3rd edn, New York: Marcel Dekker.

Goodman, L.A. (1954) 'Kolmogorov-Smirnov tests for psychological research', Psychological Bulletin 51: 160-168.

Hanssen-Bauer, I., Drange, H., Førland, E.J., Roald, L.A., Børsheim, K.Y., Hisdal, H., Lawrence, D., Nesje, A., Sandven, S., Sorteberg, A., Sundby, S., Vasskog, K. and Ådlandsvik, B. (2009) 'Klima i Norge 2100. Bakgrunnsmateriale til NOU Klimatilpassing', Norsk klimasenter, September 2009, Oslo, from www.nou-klimatilpassing.no/Klima_Norge_2100_fUR-M.pdf.file, accessed 1 May 2010. 
Haug, O., Dimakos, X.K., Vårdal, J.F., Aldrin, M. and Meze-Hausken, E. (2011) 'Future building water loss projections posed by climate change', Scandinavian Actuarial Journal 1: 1-20.

Hecht, S.B. (2008) 'Climate change and the transformation of risk: Insurance matters', UCLA Law Review 55: $1559-1620$.

Mills, E. (2005) 'Insurance in a climate of change', Science 309: 1040-1044.

Mills, E. (2009) 'A global review of insurance industry responses to climate change', The Geneva Papers on Risk and Insurance - Issues and Practice 34: 323-359.

Orskaug, E., Scheel, I., Frigessi, A., Førland, E., Guttorp, P., Haugen, J.E., Tveito, O.E. and Haug, O. (2011) 'Evaluation of a dynamic downscaling of Norwegian precipitation', Tellus A 63: 746-756.

Phelan, L., Henderson-Sellers, A. and Taplin, R. (2010) 'Climate change, carbon prices and insurance systems', International Journal of Sustainable Development and World Ecology 17: 95-108.

Scheel, I., Ferkingstad, E., Frigessi, A., Haug, O., Hinnerichsen, M. and Meze-Hausken, E. (2011) $A$ Bayesian hierarchical model with spatial variable selection: The effect of weather on insurance claims. Derivation of distributions and MCMC sampling schemes, Tech. Rep. 2, Department of Mathematics, University of Oslo. Statistical Research Report, ISSN 0806-3842, No. 2.

Scheel, I., Ferkingstad, E., Frigessi, A., Haug, O., Hinnerichsen, M. and Meze-Hausken, E. (2012) 'A Bayesian hierarchical model with spatial variable selection: The effect of weather on insurance claims', Journal of the Royal Statistical Society Series C (Applied Statistics), in press.

Vellinga, P., Mills, E., Berz, G., Bouwer, L., Huq, S., Kozak, L.A., Palutikof, J., Schanzenbächer, B., Soler, G., Benson, C., Bruce, J., Frerks, G., Huyck, P., Kovacs, P., Olsthoom, A., Peara, A. and Shida, S. (2001) Insurance and other financial services, Chapter 8 of Climate Change 2001: Impacts, Adaptation and Vulnerability, Contribution of Working Group II to the Third Assessment Report of the Intergovernmental Panel on Climate Change, www.grida.no/climate/ipcc_tar/wg2/321.htm.

\section{About the Authors}

Ida Scheel has an MSc in industrial mathematics from the Norwegian University of Science and Technology in Trondheim. She received her PhD in statistics at the Department of Mathematics of University of Oslo in 2008 where she is now working as an Associate Professor.

Mikkel Hinnerichsen holds a Cand. Scient (MSc) in statistics from the University of Oslo. He is currently working as an analyst within non-life insurance at Gjensidige Forsikring in Oslo. 